\title{
Commentary
}

\section{The absorbing life of bile acids}

\section{Joanne Marks $^{1, *}$}

joanne.marks@ucl.ac.uk

${ }^{1}$ Neuroscience, Physiology and Pharmacology, University College London, London, UK

*Correspondence: Joanne Marks, University College London, Neuroscience, Physiology and Pharmacology, London, UK.

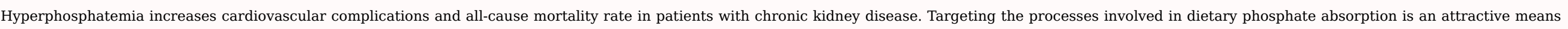

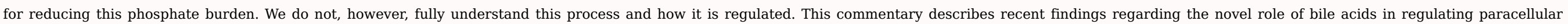
phosphate (and calcium) absorption by the small intestine and the potential cellular mechanisms involved.

see basic research on page $\mathrm{xxx}$

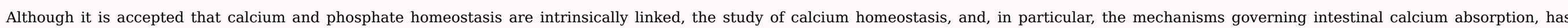

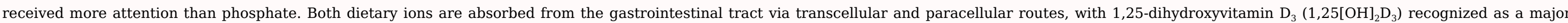

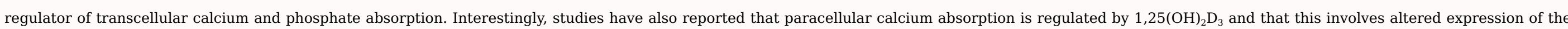

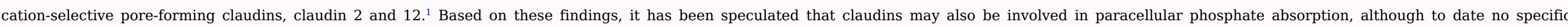

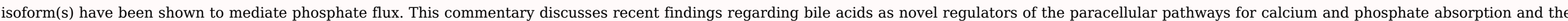
potential regulators of these processes, including the involvement of the gut microbiome.

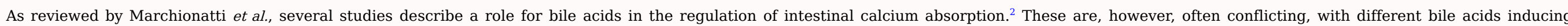

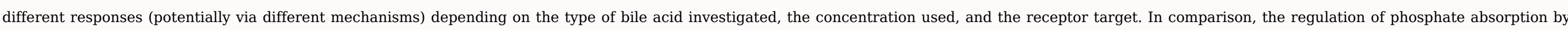

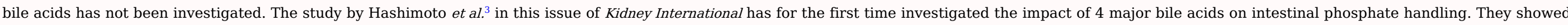

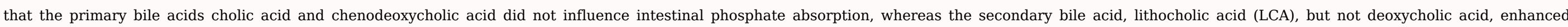

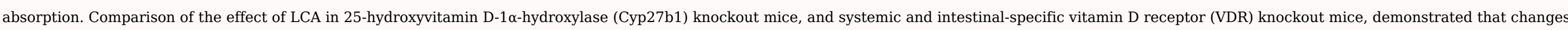

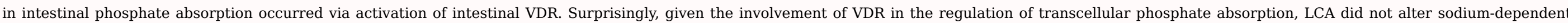

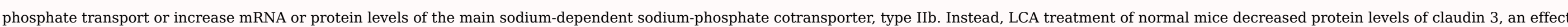

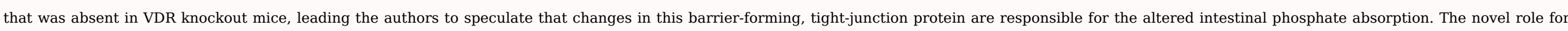
claudin 3 in paracellular phosphate absorption was subsequently confirmed with claudin 3 knockout mice, which had increased phosphate absorption in the jejunum, ileum, and colon.

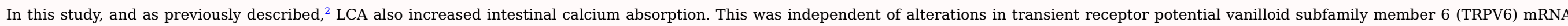

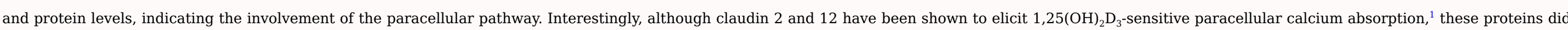

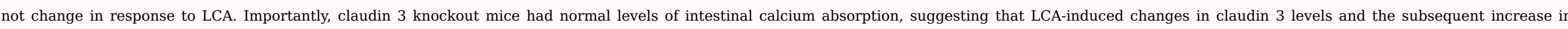

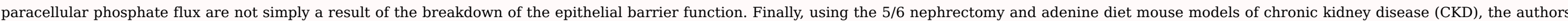
demonstrated that the LCA-induced increase in paracellular calcium and phosphate absorption exacerbated medial vascular calcification.

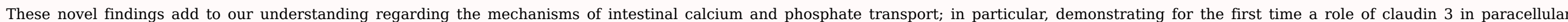




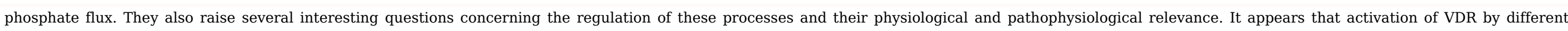

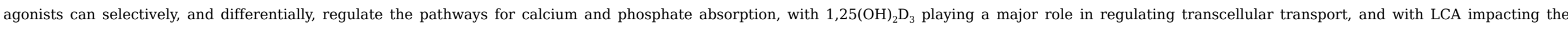

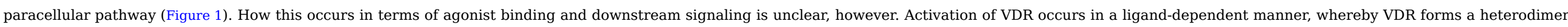

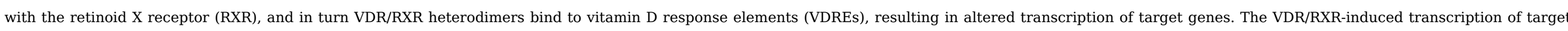

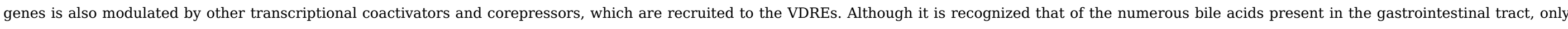

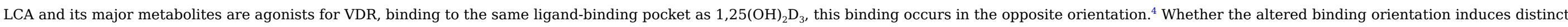
VDR/RXR complexes and cofactors that result in different downstream events compared with $1,25(\mathrm{OH})_{2} \mathrm{D}_{3}$ requires clarification.

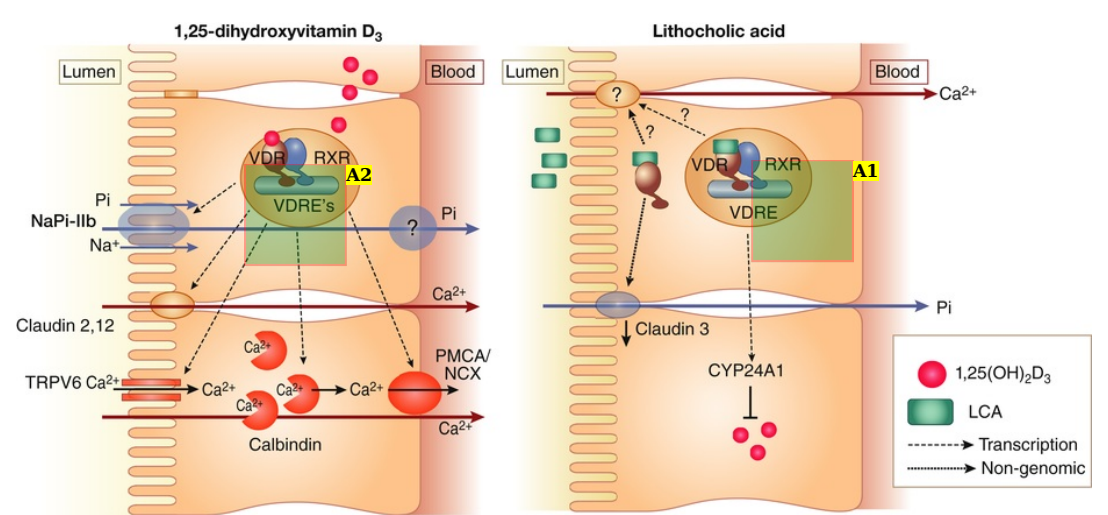

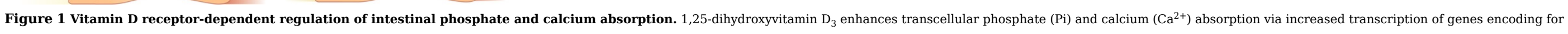

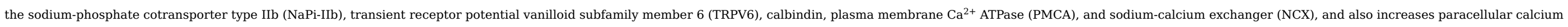

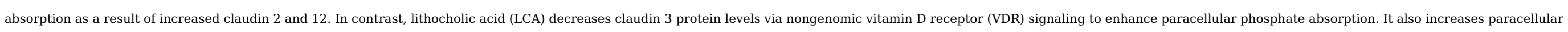
calcium absorption, but the mechanisms are unknown.

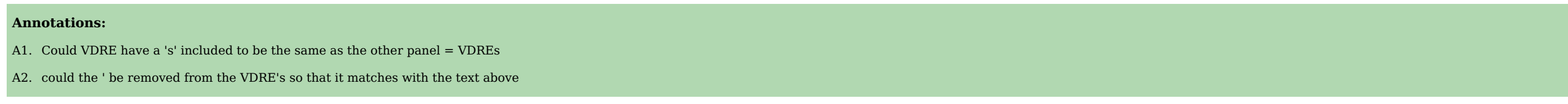

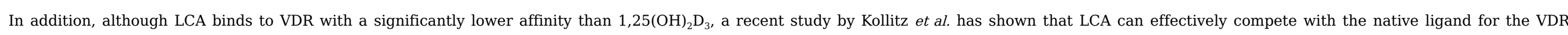

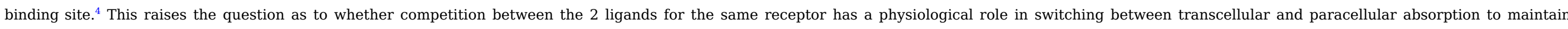

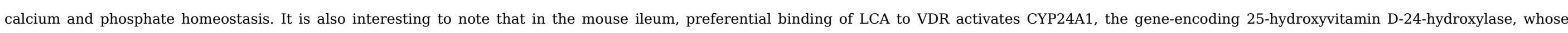

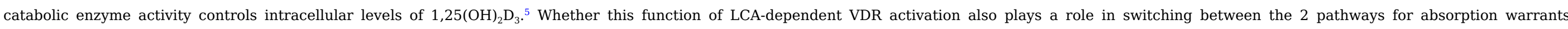

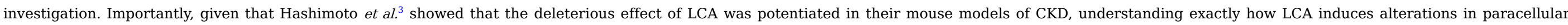
calcium and phosphate flux makes for an attractive novel therapeutic target for treating the vascular calcification commonly seen in patients with CKD.

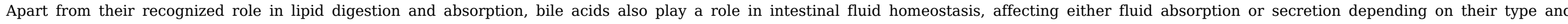

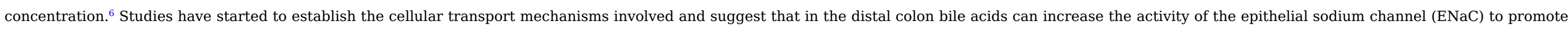

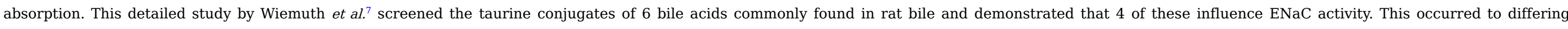

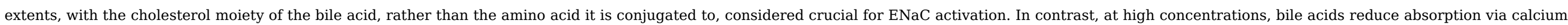

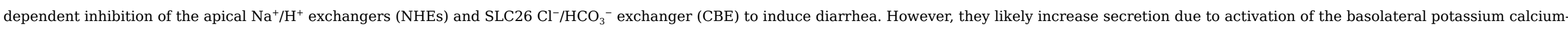

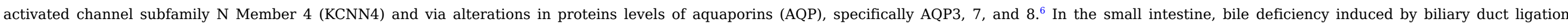




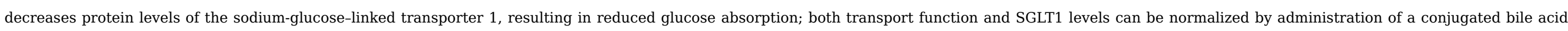

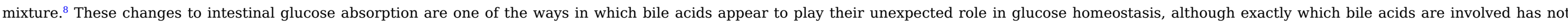

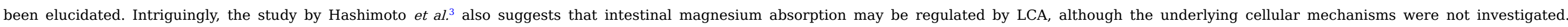

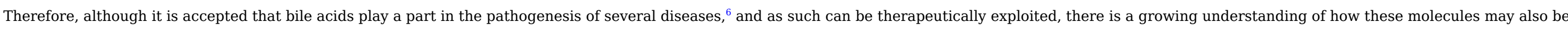

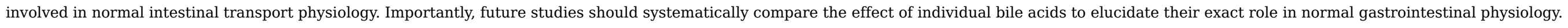

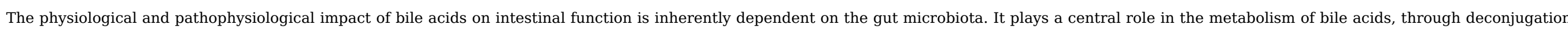

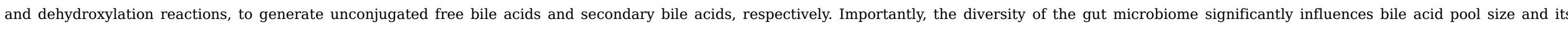

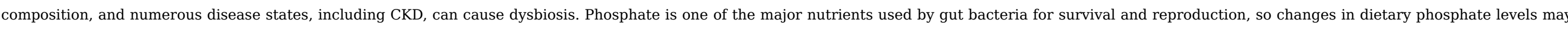

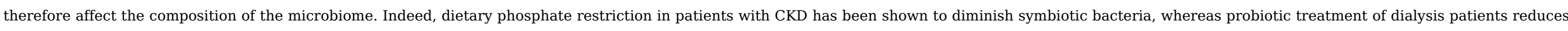

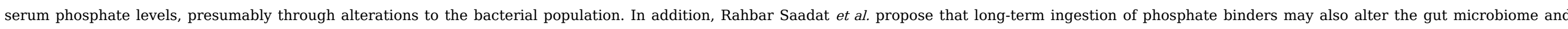

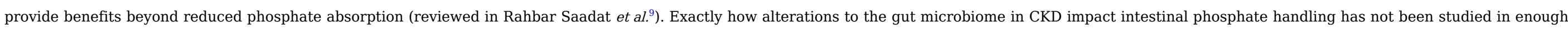

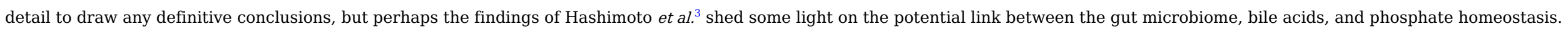

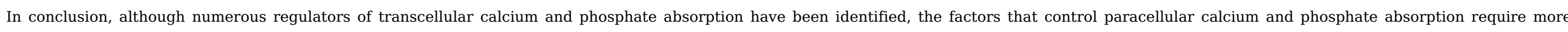

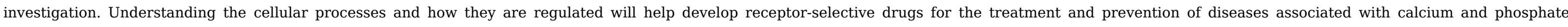
homeostatic dysregulation.

\section{Disclosure}

The author declared no competing interests.

\section{References}

1. R.T. Alexander, J. Rievaj and H. Dimke, Paracellular calcium transport across renal and intestinal epithelia, Biochem Cell Biol 92, 2014, 467-480.

2. A. Marchionatti, M. Rivoira, V. Rodriguez, et al., Molecular mechanisms triggered by bile acids on intestinal Ca2+ absorption, Curr Med Chem 25, $2018,2122-2132$.

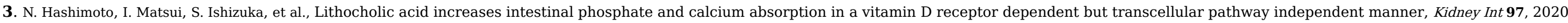
XXX-XXX.

4. E.M. Kollitz, G. Zhang, M.B. Hawkins, et al., Evolutionary and functional diversification of the vitamin D receptor-lithocholic acid partnership, PLoS One 11, 2016 , e0168278.

5. M. Ishizawa, D. Akagi and M. Makishima, Lithocholic acid is a vitamin D receptor ligand that acts preferentially in the ileum, IntJ Mol Sci 19, $2018,1975$.

6. P. Hegyi, J. Maléth, J.R. Walters, et al., Guts and gall: bile acids in regulation of intestinal epithelial function in health and disease, Physiol Rev 98, $2018,1983-2023$.

7. D. Wiemuth, C.M. Lefèvre, H. Heidtmann and S. Gründer, Bile acids increase the activity of the epithelial Na+ channel, Pflugers Arch 466, 2014, $1725-1733$.

8. Y. Du, H. Chen, Z. Xuan, et al., Bile deficiency induces changes in intestinal glucose absorption in mice, Surgery 160, $2016,1496-1507$.

9. Y. Rahbar Saadat, B. Niknafs, S.M. Hosseiniyan Khatibi, et al., Gut microbiota; an overlooked effect of phosphate binders, EurJ Pharmacol 868, $2020,172892$.

\section{Queries and Answers}

Query: If there are any drug dosages in your article, please verify them and indicate that you have done so by initialing this query Answer: JM 
Query: Do you wish to include a middle initial?

\section{Answer: No}

Query: Please confirm affiliation is correct as set with department/section listed before institution.

Answer: Please change to 'Department of Neuroscience, Physiology and Pharmacology' both here and in the correspondence address

Query: can you please provide street address and zip code.

Answer: Rowland Hill Street, NW3 2PF

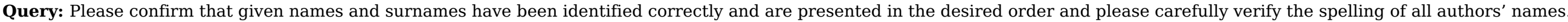
Answer: Yes 